\title{
La dérive
}

Françoise Verrey Bass

Correspondance:

Dr Françoise Verrey Bass Plänkestrasse 12

CH-2502 Bienne

fraverrey[at]gmx.ch
Entre l'an de grâce 2050 et l'an de perte 2090 la spirale de toutes choses se mit à tourner de plus en plus vite. Les années devinrent des mois, ceux-ci des jours. Les saisons perdirent leur orientation, car plus rien ne ressemblait au siècle d'avant.

Il y eut des périodes de canicule au mois de décembre et en mars. En 2067 on mesura un record de froid de moins $27^{\circ}$ degrés sur le plateau une nuit de la Sain-Jean, en plein cœur de ce que l'on nommait dans le temps l'été.

Les gens continuaient de chercher du travail, mais pas pour de l'argent. Celui-ci ne circulait plus. Du moins pour $95 \%$ de la population. Il s'agissait simplement de s'occuper, pour ne pas devenir fou.

Les maisons tombaient en ruine. On perdait le savoir de la construction. On perdait le savoir en général, car les premiers qui avaient été licenciés du monde du travail étaient ceux qui savaient comment faire. Mais ils avaient plus de 50 ans et ils coûtaient trop cher au grand patron qui se cachait derrière le nom de la société anonyme. Après avoir $\mathrm{x}$ fois délocalisé, pour payer ses ouvriers encore moins cher, il les avait remplacés par quelques robots. Les autres $5 \%$ de patrons avaient fait la même chose. Puis ils étaient partis. Finalement sans l'argent qu'ils avaient caché, ou fait fondre, ou mis en bourse, ce qui revient au même, une bourse géante, enfouie dans un volcan géant, le plus grand. C'est là que le reste de l'argent avait fondu, dans le magma brûlant.

\section{«Leurs robots faisaient tout.»}

Les gens du peuple, donc les $95 \%$ de la population, firent ce qu'ils pouvaient. Il fallait se protéger $\mathrm{du}$ soleil torride et de la pluie glaciale. Ils retournèrent habiter dans les cavernes. Ils les agrandissaient en grattant la terre avec des outils de fortune ou même avec leurs ongles. Un outil de fortune était un os bien acéré ou une pierre pointue.

Tant que ce fut possible chacun essaya d'améliorer son quotidien avec le troc. Mais il n'y eut bientôt plus rien à troquer. Les gens ne voulaient plus de choses inutiles et les choses utiles étaient tombées en poussières, puisqu'il n'y avait personne pour les réparer.

Pendant quelque temps les gens rêvèrent de vacances au bord de la mer, de voyages dans le ventre d'un étrange oiseau géant. D'autres rêvèrent de moissons faites en été, de chants, de danses. Puis ils oublièrent. Leur horizon se rétrécissait. Et puis leurs yeux en perdant de jour en jour plus de leur éclat voyaient aussi de moins en moins. C'était la même chose avec leurs oreilles. Les saisons ne se distinguant plus les unes des autres, les oiseaux disparurent, puis les autres bruits de la nature. Il n'y eut bientôt plus rien à entendre. Alors ils perdirent la faculté de l'ouie.

Assis dans leurs cavernes ils oublièrent de parler, de communiquer entre eux.

Ils n'avaient plus rien à se dire. Tenant compte que les souvenirs commençaient à s'effacer, même les plus loquaces n'avaient plus rien à raconter. Alors les femmes s'arrêtèrent de mettre des enfants au monde. Elles ne savaient plus comment et les hommes avaient oublié que pour concevoir elles avaient besoin d'eux.

Le monde se vida.

Peut-on dire que les 5\% restants qui avaient l'argent avant de le mettre dans la grande bourse furent les gagnants?

Faut-il parler de survivants? de chanceux? de malheureux?

Ils se mirent en route avec leurs robots. Ils n'avaient plus rien à perdre. Ils allèrent par monts et par vaux. D'abord dans leurs grandes voitures. Avec leurs robots. Ils ne manquèrent de rien. Leurs robots faisaient tout. Ou presque tout. Ce qu'ils ne faisaient pas, personne ne le faisait à leur place. Mais cela ne jouait pas de rôle, on n'en avait plus besoin.

Et puis les 5\% ne se rendirent pas compte que les robots n'ont que l'intelligence de leurs constructeurs. Pire, ils ne se rendirent pas compte qu'ils avaient eux-mêmes saboté leur avenir en renvoyant les constructeurs qu'ils avaient trouvés trop cher et dont ils s'étaient débarrassés grâce au mot magique «globalisation».

Plus tard les routes redevenues des chemins, le reste des $5 \%$ avançait en grimaçant accompagné de leur robot personnel, s'il fonctionnait encore, les autres et les voitures avaient rendu l'âme.

Après avoir détruit avec leur restructuration tout ce qui pouvait être détruit, le reste des $5 \%$ restant ne profitait plus de son argent qui ne servait plus à rien là où il était. De toute manière il faisait de plus en plus froid, le soleil se mourrait.

Ce n'était peut-être pas en 2090, mais quelques décennies plus tard. Cela ne joue aucun rôle. A la vitesse où nous faisons progresser les choses, cela arrivera vite.

Il aurait fallu y penser... écouter

Il aurait fallu! Peut-être... 